\title{
De quem é este bebê?': Movimento social de proteção do direito de mães e bebês juntos, com vida digna!
}

Whose baby is this?: Social movement to protect rights of mothers and babies together, with worthy life!

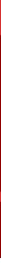

\section{Clara Karmaluk}

Comunicóloga, doula do ISHTAR-BH, ativista da Parto do Princípio.

E-mail:claralak@gmail.com

\section{Sônia Lansky}

Médica pediatra, doutora em Saúde Pública pela UFMG, ex-Coordenadora da Comissão Perinatal da SMSA-BH.

E-mail: sonialansky@gmail.com

\section{Márcia Parizzi}

Médica pediatra, doutora em Saúde da Criança e do Adolescente pela Faculdade de Medicina UFMG, Ex-Coordenadora de Atenção à Saúde da Criança e do Adolescente da SMSA-BH.

E-mail:marciaparizzi@gmail.com

\section{Gláucia Batista}

Assistente Social, mestre em Ciências da Saúde, Conselheira Estadual de Saúde. Email:glauciafb@yahoo.com.br

\section{Resumo}

Em Belo Horizonte (BH) filhos de mães, na maioria negras e pobres, com histórico de uso de álcool e outras drogas, trajetória de rua ou sofrimento mental, estão sendo separados de suas mães, ainda na maternidade. Os profissionais de saúde, pressionados pelas recomendações 5 e 6 de 2014 da 23a Promotoria de Justiça da Infância e Juventude Cível de BH passaram a avaliar a aptidão/inaptidão da mãe para o cuidado com o filho na internação. As mães se viram obrigadas

\section{Egídia Almeida}

Advogada, mestre em Direito Constitucional pela UFMG. Membro do Programa Pólos de Cidadania - Faculdade de Direito da UFMG.

E-mail:egidhu@gmail.com

André Luiz Freitas Dias

Psicólogo, doutor em Ciências, professor e Coordenador do Programa Polos de Cidadania da UFMG.

E-mail: alfreitasdiasufmg@gmail.com

\section{Cláudia Natividad}

Psicóloga, doutora em Análise de Discurso, professora de Psicologia das Faculdades Ciências Médicas e Fead. Conselheira do CRP-MG.

E-mail:claudianati@hotmail.com

\section{Bruno Pedralva Gomes}

Médico de família e comunidade, preceptor do PRM em MFC do Hospital Metropolitano Odilon Behrens, Presidente do Conselho Municipal de Saúde de BH.

Email:bpedralva@gmail.com

a provar sua inocência e capacidade de cuidar do filho, em um contexto no qual seu passado pesa desproporcionalmente sobre sua possibilidade de futuro. O movimento "De quem é este bebê?" trouxe visibilidade e concretizou ações de enfrentamento às situações de violação de direitos de mães, bebês e famílias, tendo em vista o aumento expressivo do número de recém-nascidos retidos nas maternidades e de bebês abrigados em $\mathrm{BH}$ e, segundo a Defensoria Pública de MG, 
aceleração dos processos de adoção. Este movimento envolve atores de diversas entidades e práticas de cidadania, comprometidos com a defesa dos direitos das populações em situação de vulnerabilidade e defesa da ética profissional em saúde. O movimento desvela ações de abuso de poder de autoridade do judiciário por meio de intervenções higienistas como exemplo contemporâneo do biopoder em detrimento dos direitos plenos de cidadania. Atua em defesa dos direitos da mulher à maternidade segura, com assistência digna e livre de qualquer discriminação, do direito das crianças ao nascimento respeitoso, do incentivo à convivência familiar e contra o abrigamento compulsório antes de esgotadas todas as possibilidades e deveres do Estado de proteção social e de cuidado em saúde.

Palavras-chave: Adoção; Violência contra a Mulher; Gênero e Saúde; Violações dos Direitos Humanos; Gestantes

\section{Abstract}

: In Belo Horizonte (BH) children of social excluded mothers, mostly black and poor, history of alcohol and other drugs use, street living trajectory or mental suffering, are being separated from their mothers, right after birth, still in the maternity ward. Health professionals, under pressure from the 5th

\section{Introdução}

Na história da humanidade o afastamento de mães e bebês é recorrente como expressão da discriminação de gênero, racial, da perseguição política e do moralismo. O movimento higienista na história da saúde pública incorreu nesta arbitrariedade e discriminação em diversas situações, separando familiares e cometendo injustiças. Exemplos ocorreram com a retirada de filhos de pessoas com and 6th recommendations 2014 of the 23rd Public Prosecutor's Office for Children and Youth, began to evaluate the aptitude or inability of the mothers to care for the child within in the maternity hospital. Mothers have been forced to prove their innocence and ability to care for their child, in a context in which their past weighs disproportionately on their future possibility. The movement "Whose baby is this?" Brings visibility and concrete actions to face situations of violation of the rights of mothers, babies and families to stay together, according to the significant increase in number of newborns retained in maternity wards and babies sheltered in $\mathrm{BH}$ and, as publicized by the Public Defenders of MG, acceleration of the adoption processes. This movement involves actors from various entities and citizens, committed to defend the rights of vulnerable populations and defend professional ethics in health. The movement uncovers actions of abuse of power of judicial authority through hygienic health interventions as a contemporary example of biopower, to the detriment of full citizenship rights. It acts in defense of the rights of women to safe motherhood, with dignity and respectful care, free from any kind of discrimination, the right of children to respectful birth, encouragement of family coexistence and against compulsory shelter before achieving all possibilities and duties of social protection by the State.

Keywords: Adoption; Violence against women; gender and health; Human Right Violation; Pregnancy

hanseníase, tuberculose e sofrimento mental. Como contraponto, a Constituição de 1988 e o Sistema Único de Saúde (SUS) marcam a história brasileira com os princípios da universalidade, igualdade e equidade como direitos de cidadania, com a humanização da assistência à saúde e o reconhecimento dos sujeitos de direitos e os deveres do Estado de proteção social. Esse referencial deve reger as 
práticas de cuidado com as pessoas, em especial o cuidado em saúde.

Em Belo Horizonte (BH) a atuação higienista promovida pelo Estado tem ocorrido com uma nova faceta: filhos de mulheres, na sua maioria negras, pobres, com histórico de uso de álcool ou outras drogas ou sofrimento mental estão sendo separados de suas mães, ainda na maternidade, na rede do SUS. Isto vem acontecendo, sobretudo, após as Recomendações 05 e 06 de $2014^{2,3}$ da 23a Promotoria de Justiça da Infância e Juventude Cível de $\mathrm{BH}$ e, posteriormente, da Portaria 03 da Vara Cível da Infância e Juventude de Belo Horizonte (VCIJBH) de 25 de julho de $2016 .{ }^{4}$ As Recomendações da promotoria foram dirigidas, respectivamente, aos profissionais das maternidades e dos centros de saúde da rede SUS-BH, para que notificassem à VCIJBH todas as mulheres gestantes ou puérperas usuárias de drogas atendidas nestes serviços de saúde. A Portaria de 2016, que substituiu as referidas Recomendações, determinou a comunicação à VCIJBH de situação de "grave risco" dos genitores e/ou recém-nascido, inclusive a dependência química ou trajetória de rua, em 48 horas, pelo profissional de saúde da maternidade. Este artigo relata a experiência do movimento "De quem é este bebê?", criado em BH em 2014, para dar visibilidade e concretizar ações de enfrentamento aos fluxos instituídos tanto pelas Recomendações 05 e $06^{2,3}$ quanto pela Portaria 03/VCIJBH/2016. ${ }^{4}$ Esta Portaria foi suspensa em agosto de 2017 como resultado da pressão deste movimento. Está em curso uma proposta de minuta de outra Portaria para sua substituição ${ }^{5}$, que tem sido também amplamente questionada. Persiste o debate e controvérsias sobre as suas consequências e, sobretudo, persistem os abrigamentos compulsórios e questionáveis.

O movimento "De quem é este bebê?" ${ }^{1}$ é uma resposta de resistência a estas normatizações que resultaram em gravesviolações dos direitos das pessoas e interferência no trabalho em saúde. Desde 2014 houve aumento expressivo dos casos de separação de mães e bebês por judicialização com a retenção dos bebês nas maternidades pelos serviços social e psicologia, tornando-os impedidos de saírem com sua família apesar da alta clínica ou alta médica. Os profissionais de saúde das maternidades, pressionados pelas recomendações e pela portaria, passaram a julgar a "aptidão" da mãe para o cuidado com o filho. A mãe, por sua vez, é obrigada a provar a sua inocência e sua capacidade de cuidar do filho, em um contexto no qual seu passado pesa desproporcionalmente sobre a sua possibilidade de futuro.

Segundo relatos das mulheres, neste momento de maior fragilidade física e emocional do pós-parto, elas passaram a ter que sair da maternidade em busca de documentações diversas, laudos e consultas para comprovar o contraditório. Sentiram-se desamparadas e sem defesa. Viveram situações de ameaças, culpabilização e humilhação, com prejuízo da vinculação com 
seu filho e do aleitamento materno devido ao afastamento do contato com seus recémnascidos. Ao invés de se beneficiarem da presunção de inocência, essas mulheres têm sido sumariamente julgadas e condenadas, sem cometer nenhum crime. Frequentemente são convidadas a se retirar das maternidades enquanto seus bebês ficam retidos.

A maternidade, por meio do serviço social e psicologia, encaminha para a Vara da Infância relatórios frágeis e com análise superficial sobre a situação da mulher para embasar as decisões de abrigamento e suspensão do poder familiar, elaboradas em curto tempo de conhecimento sobre a sua complexa história e realidade de vida, culminando com o encaminhamento do bebê para uma instituição de acolhimento.

Nesse processo, leitos que deveriam se destinar aos bebês com demandas clínicas e necessidade de acompanhamento hospitalar são utilizados para retenção de bebês clinicamente saudáveis, mas afastados de suas mães para aguardar decisão judicial e a liberação de vaga em instituição de acolhimento, os abrigos. Muitas vezes até mesmo leitos em unidades de cuidado intensivo são ocupados por bebês saudáveis e esses são privados dos direitos a acompanhante e cuidados maternos e da família, como assegurado pelo Estatuto da Criança de $1990 .^{6}$

Sabe-se que a vinculação de mãe e filho nos primeiros dias e meses pós-nascimento, o afeto e o aleitamento materno são de extrema importância para esse novo cidadão em formação. Não há evidência que justifique a separação protocolar de mãe e bebê, assim como o impedimento ao aleitamento materno, mesmo em caso de uso de medicamentos ou outras substâncias. Cada caso deve ser avaliado em sua particularidade e contexto com a construção de um projeto terapêutico específico.

Uma vez abrigados, os bebês também são privados do aleitamento, já que as visitas maternas nas instituições de acolhimento se limitam a poucas horas semanais, o que interfere de maneira definitiva na amamentação, no vínculo, com perdas nutricionais e emocionais para o bebê e para a mãe. Não raro, as visitas são proibidas, mesmo sem ordem judicial, acarretando uma separação por meses e, em muitos casos, para sempre. Os danos às mães e aos bebês são irreparáveis. Além da dor imensa infligida a essas mulheres, essas situações de ameaça e separação familiar criam indivíduos desconectados de suas histórias de nascimento. Crianças institucionalizadas em vez de pertencentes à sua família, seja ela nuclear ou extensa, podem crescer com uma narrativa distorcida de abandono e negação do seu direito de convivência familiar e comunitária.

Estas normativas representaram a institucionalização da discriminação da pobreza e foram direcionadas apenas para as 
maternidades públicas e para Atenção Primária em Saúde do SUS-BH, explicitando a discriminação de classe e raça/cor/etnia, já que os serviços ambulatoriais ou maternidades, de caráter privados, não sofreram a pressão dessa determinação e as mulheres das classes sociais privilegiadas não foram questionadas ou atingidas.

A construção da resistência - o movimento social como testemunho e história viva da proteção de direitos de mães e bebês.

Segundo relatos de diversas fontes na cidade, incluindo a Secretaria Municipal de Políticas Sociais, houve incremento importante do número de abrigamentos a partir de 2014, especialmente após as recomendações da Promotoria e portaria do Judiciário, assim como a aceleração do processo de adoção. ${ }^{7,8}$ Diante dessa situação, qual foi a reação da sociedade civil ao abuso da ação judicial? Qual foi a reação da sociedade quando os relatos dessas mães surgiram na cidade? Quando surgiram narrativas de mulheres vulnerabilizadas que sequer tiveram o seu direito de defesa? Que mobilização pode surgir quando a judicialização das situações de grave vulnerabilidade e violações de direitos humanos de grupos específicos e habitualmente excluídos interferem nas políticas de saúde e têm implicações éticas graves para os trabalhadores em saúde do município?

A separação de bebês de suas famílias traz inúmeros efeitos deletérios sobre esses sujeitos, com sofrimentos e adoecimentos desnecessários e injustos, incluindo reinternações e até mortes de bebês em abrigos. Como ignorar, como não se comover com o estado de desespero das mulheres na expectativa da chegada de um bebê e com a volta para casa de mãos vazias? 0 testemunho em tempo real de abrigamentos injustos e em número crescente de crianças gerou conflitos com os propósitos da atuação ética dos profissionais de saúde e mobilizou mulheres e homens indignados, que iniciaram em Belo Horizonte o movimento "De quem é este bebê?." ${ }^{1}$ Este reúne pessoas que atuam na defesa e apoio às "mães órfãs": mulheres em situação de vulnerabilidade que perderam seus bebês, tentaram e tentam exercer o seu direito à maternidade. 0 movimento entende que cumprir as determinações judiciais, ignorando a situação peculiar de extrema vulnerabilidade e excepcionalidade dessas mães é ferir os códigos de ética profissional e a diretriz democrática dos princípios norteadores do SUS. A universalidade garante o direito à saúde a todos os brasileiros, sem discriminação. A integralidade garante ações contínuas no sentido da promoção, da proteção, da cura e da reabilitação da saúde. A equidade trata da prioridade de grupos sociais mais vulneráveis ao cuidado em saúde. O movimento "De quem é este bebê?" respalda o dever do trabalhador da saúde de priorizar a assistência integral para as mulheres de modo a aproximá-las e não afastá-las dos serviços de saúde. E foi com o compromisso com a prática assistencial em saúde que esses trabalhadores começaram a questionar as normativas e se organizaram em 
rede para evitar a separação injusta de mães e bebês. As pessoas envolvidas com esse movimento defendem que a situação de separação de mãe e bebê deve ser considerada uma excepcionalidade, cabível somente nos casos de real necessidade, após esgotadas todas as possibilidades de apoio e proteção à maternidade, à infância, à cidadania das famílias. Cada caso deve ser avaliado de forma particular, individual, consideradas as peculiaridades de cada situação, as demandas reais de tratamento identificados a partir da escuta cuidadosa da mulher. $\mathrm{O}$ atendimento, $\mathrm{o}$ cuidado e a atenção devem ser feitos em rede e de forma interdisciplinar e intersetorial, tendo em vista a condição de vulnerabilidade socioeconômica de, praticamente, a totalidade dos casos.

Conflitos de interesse foram desvelados nesta complexa situação. Segundo a Defensoria Pública de MG, há um fator agravante com a avaliação das famílias das crianças abrigadas pela mesma equipe técnica que avalia e acompanha as famílias que buscam a adoção. Dessa forma, estes técnicos sofrem forte influência e talvez a ilusão de que as possibilidades econômico-sociais que estas crianças teriam, se inseridas em famílias de maior poder aquisitivo, poderiam resultar em maior felicidade. Outro conflito de interesse ressaltado pelas entidades que compõem o movimento é o financiamento das instituições de acolhimento de bebês conveniadas ao poder público municipal, que recebem remuneração mensal de valores em torno de $\mathrm{R} \$ 3.000,00$ per capita. Pergunta-se: por que esses recursos não são utilizados em políticas públicas para dar suporte às famílias em situação de vulnerabilidade para a melhoria da sua condição de vida, vinculação e cuidados necessários a essas crianças e suas mães? Todo o investimento deveria priorizar a prevenção da separação de bebês do convívio familiar e comunitário, e não promover o abrigamento das crianças como solução para a sua situação de vulnerabilidade. Aparentemente resolve-se o problema da criança e abandona-se a mulher e a família à própria sorte.

A ação da Defensoria Pública de $M G$ foi contundente. Alertava a ocorrência de abrigamentos desnecessários nas maternidades sem a escuta e a defesa apropriada da mãe e da família pela Defensoria, que só era acionada, em média, três meses após o acolhimento da criança. Várias discussões foram realizadas com as maternidades, profissionais de saúde e entidades, entre elas o Conselho Regional de Psicologia, Conselho Regional de Assistência Social, Conselho Municipal de Saúde, Conselho Estadual de Saúde da Mulher e Defensoria Pública, que exaustivamente divulgava o direito dessas mulheres de serem defendidas.

A primeira resposta institucional às recomendações da Promotoria da Infância foi o Ofício no 76/2014 da Comissão Perinatal da SMSA $^{9}$ dirigido a todas as maternidades e profissionais da cidade, com encaminhamentos consensuados por diversas entidades, inclusive 
da Defensoria Pública da Infância de MG. Orientava que as maternidades mantivessem a articulação com a rede de atenção no território da família, Centros de Saúde e de Assistência Social, responsáveis pela continuidade do cuidado integral à saúde da mulher e da criança após o parto e garantia de proteção social (renda, educação, moradia, alimentação) às mulheres e suas famílias. Destacava que não é função da maternidade avaliar e definir sobre a situação de vida e capacidade de cuidados da mulher com a criança.

Os Conselhos de Direitos e o Conselho Municipal de Saúde se apropriaram do problema, questionaram as Recomendações da Promotoria e a possível violação de direitos dessas mulheres e crianças com a ruptura da vinculação mãe-bebê e família. Um manifesto fundamentado na Constituição Federal de 1988, no ECA ${ }^{6}$, na Política Nacional de Atenção Integral aos Usuários de Álcool e outras Drogas, nos códigos de ética profissional e no Programa Nacional de Direitos Humanos ${ }^{10}$ foi organizado pelo Conselho Estadual da Mulher e assinado por 29 entidades, solicitando a imediata suspensão das Recomendações, desvelando e repudiando a violência institucional sofrida por essas mulheres e seus filhos. ${ }^{11}$

Além de cidadãos mobilizados, em especial profissionais da área da saúde e do direito, cerca de trinta entidades e representantes da sociedade se agregaram ao movimento "De quem é este bebê?": Centro de Defesa da Criança e do Adolescente de Minas Gerais;
Centro Nacional de Defesa de Direitos Humanos da População em Situação de Rua; Catadores de Material Reciclável; Conselho Estadual de Saúde; Conselho Estadual da Mulher; Conselho Municipal de Saúde de Belo Horizonte; Conselho Regional de Psicologia; Conselho Regional de Serviço Social; Defensoria Especializada em Direitos Humanos Socioambientais e Coletivos; Defensoria da Infância e Adolescência Cível de Minas Gerais; Fórum de Mulheres do Mercosul; Fórum de População de Rua; Fórum Mineiro de Direitos Humanos; Fórum Mineiro de Saúde Mental; Frente de Defesa dos Direitos da Criança e do Adolescente; Frente de Defesa do SUS; Marcha Mundial de Mulheres; Movimento do Graal; Oficina de Imagens; Pastoral da Criança; Pastoral do Menor; Polos de Cidadania UFMG; Rede Feminista de Saúde; Sindicato dos Jornalistas; Sindicato dos Psicólogos; Vereadora Áurea Carolina; Vereador Gilson Reis; Vereador Pedro Patrus.

O movimento tomou proporções em âmbito nacional. Contribuiu para a divulgação dos fatos ocorridos em BH, para a produção de estratégias de mobilização potente para além do município. Em dezembro de 2014 foi a BH uma comitiva oficial com representantes das Coordenações Nacionais de Saúde da Mulher e da Saúde da Criança do Ministério da Saúde, da Secretaria Nacional de Direitos Humanos e do Conselho Nacional dos Direitos da Criança e do Adolescente (CONANDA) para avaliar a gravidade da situação.

Neste mesmo ano foi realizada a primeira 
audiência pública sobre o tema na Assembleia Legislativa de Minas Gerais, como resultado da pressão social. No dia 19 de dezembro de 2014 as Defensorias Públicas da União e do Estado divulgaram a Recomendação Conjunta № $01 / 2014$ / ODHTCMG / D P D / D P J C, contestando os argumentos das Recomendações da Promotoria Pública com um arcabouço jurídico e reafirmando a necessidade de atendimento em rede e da manutenção dos fluxos já pactuados nas políticas públicas. ${ }^{12}$

O tema foi amplamente debatido na imprensa local, mas a abordagem de forma geral reforçava o viés preconceituoso da sociedade, onde bebês foram chamados, em diversas reportagens, como órfãos ou filhos "do crack". ${ }^{7,813}$ Essas mães e seus filhos sofreram violações contra sua dignidade, suas imagens e perspectivas de futuro expressas em textos preconceituosos que não reconheciam sua história de vida de exclusão e de violência.

Por um lado, um levantamento do jornal local Estado de Minas, em 2014, noventa dias após as Recomendações do Ministério Público, apontou que seriam necessários três novos abrigos na cidade pelo recente volume de abrigamentos de crianças. ${ }^{13}$ Por outro, aconteciam denúncias de processos de adoção facilitados, assim como relatos de que as mães não recebiam informação sobre seu direito ao apoio jurídico da Defensoria Pública para garantia de sua defesa. ${ }^{7,8}$ A versão oficial da 23a Promotoria de Justiça da Infância e Juventude era de que os abrigamentos, as adoções e falta de encaminhamento para a Defensoria Pública ocorriam apenas em casos extremos. ${ }^{7,8,13}$ Os números diziam o contrário e os movimentos sociais marcaram o fenômeno como uma cena de violação de direitos com abrigamentos compulsórios. Denúncias públicas em audiências na Câmara Municipal e na Assembleia Legislativa colocaram a preocupação sobre redes ilegais de adoção ou até mesmo de tráfico de bebês.

Em janeiro de 2015, o Conselho Municipal de Saúde de BH, no exercício legítimo da participação popular na política de saúde do SUS-BH, e baseado no parecer da Câmara Técnica de Saneamento e Políticas Intersetoriais N.o $151 / 2014,{ }^{14}$ se posicionou sobre o tema por meio da Resolução $n$ 은 $377 / 15^{15}$ orientando "que a Secretaria Municipal de Saúde (SMSA) não atendesse às Recomendações 05 e 06/2014. ${ }^{15}$

Ainda que sob forte pressão e influência da Promotoria da Infância e da Juventude, o Conselho Municipal de Direitos da Criança e do Adolescente de Belo Horizonte emite a Deliberação nำ11 ${ }^{16}$ em fevereiro de 2015 que reforça e aplicação da medida de acolhimento institucional em caráter excepcional e o direito à convivência familiar e comunitária, de forma a evitar a aplicação compulsória e indiscriminada da medida de institucionalização.

O movimento ganhou maior apoio institucional com a publicação da Nota Técnica Conjunta das 
Secretarias de Atenção à Saúde (SAS) e Secretaria de Gestão Estratégica e Participativa $(\text { SGEP })^{17}$ do Ministério da Saúde em setembro de 2015, contendo diretrizes para o fluxo de atenção às mulheres e famílias em condição de vulnerabilidade, respeitando seus direitos de proteção social.

A pressão do judiciário se manteve e o MP-MG moveu Ação Civil Pública contra a Secretaria Municipal de Saúde de-BH, pressionando para implementar a comunicação ao Juizado da Infância e da Juventude e ao Conselho Tutelar sobre todas as gestantes em situação de risco e, ainda, a disponibilização de leitos para as gestantes usuárias de drogas e álcool, para internação, inclusive de forma compulsória, nas redes pública ou privada. A SMSA-BH ganhou esta ação em segunda instância, assegurando assim a prerrogativa do executivo de se estabelecer os fluxos e diretrizes assistenciais da saúde, atendendo aos preceitos legais constitucionais da saúde e protegendo a ética profissional.

Assim, o movimento "De quem é este bebê?" adquiriu força jurídica e institucional e agregou entidades com atuação em direitos humanos, formando grupos de trabalho específicos para aprofundamento nas questões jurídicas e na mobilização social. Neste momento se expandiram as ações com atuação nas ruas para sensibilização da sociedade para o problema e houve participação do movimento em diversas deliberações, moções e pareceres de proteção aos direitos das mulheres e bebês junto à
Defensoria Pública, em Audiências Públicas na Câmara Municipal de $\mathrm{BH}^{18}$ e na Assembleia Legislativa de MG. ${ }^{19}$

A mobilização surtiu efeito com maior articulação da rede para atuação integrada e mais efetiva desde o pré-natal, maternidades e cuidado após o parto, assim diminuindo os abrigamento em 2016. Entretanto, em decorrência da Portaria 3 VCIJBH/2016, o cenário recrudesceu e as comunicações à Vara da Infância e abrigamentos pelas maternidades públicas aumentaram, muitas vezes antes mesmo de acionadas as ações de apoio psicossocial e intersetorial às mulheres e sua família. Muitas mães e bebês foram condenados à separação arbitrária e "preventiva" sem haver a comprovação da violação de direitos. A fila de espera nos abrigos se tornou ainda maior e, segundo relatos das próprias mães, estas eram impedidas de sair da maternidade com seus filhos, mesmo com a alta médica. Aumentaram os relatos de mulheres que praticamente fugiram das maternidades com seus filhos e diversas mulheres que não buscaram atendimento pré-natal nos Centros de Saúde ou deixaram a cidade para ter seus filhos, por receio de perderem seus bebês.

Este afastamento protocolar do bebê de sua mãe, pela simples identificação de uso de drogas pela mãe evidencia uma situação perversa na qual o diagnóstico "drogada" é justificativa para punir a mulher com a retirada do seu filho e negativa de oferta de cuidados ou 
atenção necessários diante dos desafios da vida. Conforme ressaltado por Canguilhem, Foucault e Feuerwerker"20,21,22 "essa qualificação como normal e patológico é sempre uma imposição de uns sobre outros, pois modos de existências tomados como anormais sempre são produtos da construção de relações de poder, entre distintos poderosos." ${ }^{20: 45}$ Mulheres que organizam suas vidas com lógicas distintas das majoritárias são rotuladas como diferentes e, em nome disso, são desqualificadas para a maternidade e impõem restrição à sua liberdade.

O abuso de autoridade se apresenta também de outras maneiras como, por exemplo, com o bloqueio do acesso à informação oficial sobre o número de abrigamento de bebês. Os dados levantados pela imprensa divergem. Em 2017 a Agência Pública reportou os números de bebês menores de um ano abrigados em Belo Horizonte utilizando como fonte o Conselho Nacional de Justiça e a Secretaria de Assistência Social de Belo Horizonte: 174 versus 74 (2014); 115 versus 128 (2015); 100 versus 118 (2016); 39 versus 23 (2017). De qualquer forma, apontaram, portanto, pelo menos cerca de 300 crianças nesta situação em $\mathrm{BH}^{23}$

Outra forte expressão de abuso de autoridade, discriminação e violação de direitos na perspectiva das mulheres é a recorrente sonegação de informação sobre os direitos de defesa das mulheres pela Defensoria Pública, que não era indicada para as mulheres que têm seus filhos abrigados, prejudicando o processo de manutenção do poder familiar. Há inclusive relatos de mães que foram orientadas a não buscarem recuperar a guarda de seus filhos. Outras muitas tiveram que sair da maternidade sem o seu filho, em busca de documentos e laudos oficiais para comprovar a sua capacidade de cuidar do filho, ainda durante o puerpério, período sensível física e psicologicamente. Além de todo este sofrimento, ainda tiveram seu direito de amamentar negado.

A separação é também prejudicial para as mulheres mais vulneráveis ou que estejam em recuperação da dependência química. Elas frequentemente usam as drogas como alívio da dor, frustração e ansiedade de não saber se recuperarão a guarda dos bebês antes que sejam encaminhados para adoção. Ao negar acolhimento e acesso à Saúde, o Estado assume uma postura institucional de violência contra essas mulheres já fragilizadas. Por que essas mulheres não podem ser apoiadas pelas políticas públicas até que recuperem sua saúde física e mental? Seus filhos são estigmatizados, mesmo possuindo mães ou familiares carinhosos e com desejo de cuidar deles. São vistos pela opinião pública como "abandonados", em uma situação de orfandade artificial causada pela incapacidade do Estado de proteger suas mães e os vínculos familiares.

A luta do movimento na resistência continuou se fortalecendo com diversas representações legais de entidades e parceiros políticos em Audiências Públicas, Recomendações oficiais 
de diversos órgãos e denúncias à Secretaria Nacional de Direitos Humanos. Os Ministérios da Saúde e do Desenvolvimento Social e Combate à Fome ${ }^{24}$ emitiram uma Nota Técnica e um Fluxograma de Atendimento ${ }^{25}$ reforçando os direitos das crianças e das mulheres. Em seguida, o Conselho Nacional de Saúde emitiu uma Recomendação alinhada à proposta de fluxos de cuidado envolvendo ações intersetoriais de apoio e proteção a estas mulheres, crianças e famílias. ${ }^{26}$

No nível estadual as Secretarias de Estado de Saúde de Minas Gerais (SES-MG), de Direitos Humanos, Participação Social e Cidadania e de Trabalho e Desenvolvimento Social realizaram seminário de Direitos Humanos para divulgar a Resolução Conjunta ${ }^{27}$ destinada aos Serviços Públicos de Atendimento às mulheres e adolescentes usuárias de crack e outras drogas e a seus filhos recém-nascidos.

Especificamente no âmbito da saúde, após amplo processo de debate e decisão em plenária, o Conselho Municipal de Saúde de BH reafirmou seu posicionamento e publicou nova resolução em 15/12/2016..$^{28}$ Apesar de todo o trâmite legal, democrático e legítimo de representação do $\mathrm{CMS}$ e da $\mathrm{PBH}$, o presidente do $\mathrm{CMGBH}$ em exercício foi alvo de processo criminal como provável ato de retaliação e intimidação.

A Comissão Perinatal da SMSA de BH também redigiu nova orientação às maternidades e divulgou o Fluxograma de Atendimento adotado pela Secretaria Municipal de Saúde. ${ }^{29,30}$ Essa orientação reafirmou a missão da maternidade no que tange ao cuidado no parto e nascimento, a necessidade de se processar a alta responsável e assegurar a continuidade de cuidado após o parto no território de responsabilidade onde a família reside, para evitar a internação desnecessária de mulheres e bebês saudáveis e o abrigamento de bebês. Retoma assim a responsabilidade da instituição hospitalar e não a responsabilização individual de profissionais como da assistência social ou da psicologia em quem recaía isoladamente a decisão da alta social ou administrativa. Remete ainda para a rede de cuidados da saúde e da Assistência Social e Saúde no território de moradia da gestante a responsabilidade sobre $o$ cuidado integral à mulher e família. Ressalta o que deveria ser uma boa clínica, já que não seria adequada a definição pela maternidade do futuro social das famílias.

Pressões do movimento contrário à Portaria prosseguiram. Foi proposta uma CPI para apuração de denúncia pública de tráfico de bebês ${ }^{31}$ durante audiência pública realizada na Câmara Municipal de vereadores de $\mathrm{BH}$, mas não houve a adesão de número suficiente de vereadores para a sua constituição. A Defensoria Pública de Minas Gerais ajuizou uma representação contra a Portaria 03/VCIJBH/2016 no CNJ questionando sua validade e outras representações foram efetivadas para órgãos de controle do judiciário, inclusive em fóruns de âmbito internacional. 
Em abril de 2017, o movimento sofreu retaliação com o afastamento de duas profissionais médicas pediatras da Secretaria Municipal de Saúde que exerciam liderança no posicionamento em defesa de mulheres, crianças e famílias. Houve reação dos movimentos sociais, com abaixo-assinados, ${ }^{32,33}$ realização de Plenária de Movimentos Sociais convocada pelo Conselho Municipal de Saúde com mais de 100 participantes de movimento sociais, usuários, gestores e trabalhadores do SUS, o que culminou em um manifesto público de repúdio assinado por 56 entidades da sociedade civil, entre eles os Conselhos Municipal e Estadual de Saúde, Sindicatos, Movimentos Sociais e mandatos parlamentares de vereadores, deputados estaduais e deputados federais. Diversas moções de apoio foram realizadas em congressos de âmbito nacional como o da Associação Brasileira de Saúde Coletiva (Abrasco), ${ }^{34}$ Conferências Distritais de Saúde de BH e na 14ạ Conferência Municipal de Saúde da Mulher de BH. Essa situação de intimidação das ações de defensores de direitos humanos resultou em maior mobilização e deu maior visibilidade ao movimento, com a estruturação do blog $D e$ quemé esse bebê $\hat{e}^{1}$ de página no Facebook. ${ }^{35}$

A entrada no movimento de diversos atores como os advogados populares dos Coletivos Margarida Alves e Maria Felipa, advogados e assessoria jurídica de gabinetes parlamentares como das vereadoras Áurea Carolina e Cida Falabella, vereadores Pedro Patrus e Gilson Reis, deputados estaduais Jean Freire, Marília
Campos, Antônio Jorge e Deputado Federal Adelmo Leão, dos defensores públicos, procuradores federais, da Clínica de Direitos Humanos da UFMG, do Coletivo História Incomum, do Programa Pólos de Cidadania da UFMG, do Fórum de População de Rua, do Ateliê Intervalo de Redução de Danos do Mestrado Profissional em Promoção da Saúde e Prevenção da Violência, do Observatório de Políticas e Cuidado em Saúde da Faculdade de Medicina da UFMG e de participantes da sociedade civil, bem como a participação de mães afetadas pela perda de seus filhos foi de extrema importância para a mobilização e sustentação jurídica do movimento.

Em especial, a Frente Mineira de Saúde Mental trouxe o amparo e experiência da luta antimanicomial, que enfrenta toda espécie de preconceito a que estão submetidas essas pessoas e identificou a faceta da discriminação desses sujeitos de direitos, em particular na situação de proteção do direito à maternidade.

O Fórum de População de Rua de BH aportou ao movimento um diferencial de destaque. A População em Situação de Rua, mais do que um fenômeno típico dos centros urbanos, é um fenômeno global e complexo que requer a atenção e comprometimento de setores diversos, sobretudo do poder público na garantia e implementação de serviços e políticas que assegurem os direitos básicos das pessoas que se encontram nessa situação. Belo Horizonte historicamente foi referência de serviços destinados a essa população. No 
entanto, a estagnação e retrocessos políticos e metodológicos são reais. A maioria dos serviços foi conquistada há cerca de duas décadas, incluindo a segurança alimentar e o atendimento de Consultórios de Rua. Apesar dos serviços existentes, $\mathrm{BH}$, assim como as demais capitais e grandes cidades, tem assistido quase que cotidianamente ao aumento do número de pessoas vivendo nas ruas. As políticas para esse segmento populacional devem superar as respostas provisórias, lineares e higienistas para efetivar políticas e serviços intersetoriais, com equidade e qualidade.

\section{O Programa Polos de Cidadania da Faculdade} de Direito da UFMG também se inseriu no movimento de forma expressiva. É um programa transdisciplinar e interinstitucional de extensão, ensino e pesquisa social aplicada, criado em 1995, voltado para a efetivação dos Direitos Humanos e para a construção de conhecimento a partir do diálogo entre os diferentes saberes, por meio do fortalecimento de autonomias individuais, coletivas e políticas, da inclusão e da emancipação de grupos sociais e sujeitos com histórico e trajetória de vulnerabilidade social. Tem como base metodológica principal a pesquisa-ação e compromisso com a transformação social e produção de conhecimento.

O Programa Polos foi quem reuniu as considerações de todos os membros do grupo jurídico do movimento e elaborou um estudo apresentado ao Tribunal de Justiça ${ }^{36}$ sobre a
Portaria Substitutiva ${ }^{5}$ à Portaria 03 de 2016 da Vara da Infância. A Clínica de Direitos Humanos da UFMG também redigiu documento sobre os pontos conflituosos da proposta e o próprio Conselho Municipal dos Direitos da Criança e do Adolescente de Belo Horizonte exigiu o cumprimento da Deliberação CMDCA/BH no $111^{16}$ em Nota Pública. ${ }^{37,38}$

O movimento “De quem é esse bebê?" e mães órfãs: enfoque na perspectiva da desigualdade de gênero

O movimento “De quem é esse bebê?" destaca a necessidade de promover a atenção integral e proteção das mulheres vulnerabilizadas, além das diversas formas de violências decorrentes da sua situação socioeconômica e de raça/cor e outras formas de violência de gênero. Essas mulheres têm sido tratadas de forma preconceituosa e desrespeitosa por vários serviços públicos, que as julgam incapazes e indignas de terem e cuidarem de seus filhos. Mesmo as que conseguem apoio familiar são julgadas como incapazes e muitas de suas famílias também são assim desconsideradas para efeito de concessão da guarda da criança.

Ao poder público cabe a efetiva proteção com unidades de acolhimento e de atenção para as gestantes que se encontram em situação de rua e com situação de vulnerabilidade, com respeito à sua autonomia e dignidade humana. Elas têm o direito à proteção do Estado para o seu acompanhamento pré-natal e/ou tratamentos de saúde sobre dependência 
química, se necessário, para que tenham condição física, material e emocional para cuidarem de seus filhos.

Entretanto, ações do judiciário têm sido justificadas apenas com base na proteção da criança. Os direitos individuais são reduzidos a uma interpretação enviesada do ECA. Nesta visão, os direitos da mulher são relegados a um segundo plano e mesmo os direitos da criança, quando desconsiderada a sua primeira necessidade de permanecer junto com sua mãe e família.

As normatizações da Promotoria de Justiça operam com a concepção de masculinidade hegemônica reproduzindo e sustentando a desigualdade de gênero. A instituição sustentaria o poder desigual entre as pessoas conforme origem de classe social/gênero e raça fortalecendo a desigualdade. ${ }^{39}$ A sociedade patriarcal baseia-se na essência dessa masculinidade hegemônica que forma seus membros numa socialização "genderizada" com desigualdades de poder, desigualdades sociais e de saúde que reproduzem a sociedade patriarcal fechando assim o ciclo de dominação. Isso é fato, pois as mães órfãs são consideradas com status de menor valor e tem que provar sua capacidade de serem mães, apesar de conquistas das lutas das mulheres nos últimos séculos. O biopoder de Foucault $(1988)^{40}$ é exercido neste caso pela instituição hospitalar, por meio de profissionais de saúde e na área judicial com os operadores do direito. Mas na pauta, além do gênero e classe, estão as drogas.
Pressionadas e inquiridas, essas mulheres confessam o uso e perdem o poder familiar, perdem seus filhos, acolhidos em abrigamento compulsório. Os operadores do direito e da saúde utilizam ainda concepções desatualizadas e preconceituosas na abordagem dos usuários de drogas. As questões ora engendradas deveriam ser debatidas com toda a sociedade, respeitados os poderes civis constituintes e de acordo com o arcabouço jurídico democrático ainda em vigor.

\section{As ações de mobilização social do movimento}

Um dos grandes desafios tem sido dar voz e respeitar a autonomia das mães e famílias vulnerabilizadas, o que é complexo pelo receio que elas têm de sofrer novas ações discriminatórias, por não conhecerem seus direitos ou por aceitarem em sua humildade essas violações como "naturais" num contexto de vidas precarizadas pela pobreza e pela desinformação. O movimento ampara ações que dão visibilidade às violações contra essas mulheres. Diversos atos de rua, com exposição de varal com cartazes, meias e sapatinhos de bebês pendurados, como forma de representação concreta da preparação amorosa, expressaram o vazio deixado com a ausência dos bebês. $\mathrm{O}$ ato realizado na porta da Prefeitura na semana do dia das mães contou com grande repercussão nas mídias e redes sociais. As pessoas portavam velas acesas em vigília em respeito às perdas das mães e também com o sentido de iluminar mentes e corações das autoridades locais, sensibilizando-as para a dor 
das pessoas vulnerabilizadas e a necessidade de sua inclusão nas políticas públicas (Figura 1). Foi exibido o vídeo "De quem é esse bebê" ${ }^{35}$ em telão na rua e flores foram distribuídas aos passantes. Os coletivos Linhas do Horizonte e Alvorada, com histórico de engajamento social na cidade, marcaram presença com os bordados de luta com faixas pedindo justiça para as mães. Participaram crianças, mães, famílias e profissionais de saúde e do direito, neste e nos atos que se sucederam: na 14a Conferência Municipal de Saúde, na $1 \underline{a}$ Conferência Municipal de Saúde da Mulher, na Conferência Estadual de Saúde da Mulher, na Conferência de Saúde de Passos (MG), no Congresso Mundial de Mulheres e Fazendo Gênero em Florianópolis, no encontro nacional da Central Única dos Trabalhadores e na $2^{\text {a }}$ Conferência Nacional de Saúde da Mulher em Brasília, e ainda durante a visita da Missão Nacional na porta da Faculdade de Medicina da UFMG.

As reuniões iniciais e específicas de trabalhadores da saúde no movimento "De quem é esse bebê?" e as suas conquistas foram compartilhadas e divulgadas em redes sociais e formou-se um fluxo de construção coletiva, horizontal e aberta. Como estratégia formaram-se grupos de trabalho de ação política, grupo de ação jurídica e grupo de ação técnica, que, por exemplo, vem trabalhando na questão das evidências científicas que recomendam o contato pele-a-pele imediato e o aleitamento materno logo após o nascimento, as repercussões negativas que envolvem a separação imediata de mães e bebês e a suspensão do aleitamento materno sem base técnica.

O movimento conta com diversos mecanismos de mobilização e estreitamento de redes em uma tentativa de somar esforços, dar visibilidade e fortalecer as mulheres para que cada vez menos bebês sejam abrigados antes de esgotadas todas as possibilidades de cuidado. Atualmente possui apoio político de parlamentares nas três esferas de poder. São mantidas reuniões regulares com um fluxo de construção coletiva, horizontal e aberta com participantes de diferentes áreas de formação e atuação e incentivo para a participação das mães, para ampliação da consciência sobre as violações de seus direitos, ganho de visibilidade e empoderamento enquanto grupo de mulheres que sofrem discriminação e racismo.

O aporte comunicacional é feito por meio do blog "De quem é esse bebê?"1 e a página do Facebook $^{35}$ com repositório de reportagens, documentos, principais notícias e divulgação de atos e ações de resistência. O vídeo "De quem é esse bebê?" ${ }^{41}$ teve um alcance de aproximadamente 126 mil visualizações e foi elaborado a várias mãos com o objetivo de divulgar estas situações de violência contra a mulher e o bebê.

O tema penetrou na sociedade e foi debatido em diversos fóruns da cidade como no Fórum de Violência contra a Mulher, nas comissões e conferências locais dos Centros de Saúde e dos Distritos Sanitários que se solidarizaram com o 
movimento em forma de moções escritas e cartas dirigidas à gestão e a toda a cidade. $\mathrm{O}$ movimento "De quem é este bebê?" seguiu crescendo e se fortalecendo com diversos encontros ampliados. Agregou a participação das próprias mulheres vítimas desta discriminação e uma frente específica de pesquisa e extensão da Faculdade de Direito e da Faculdade de Medicina da UFMG. Diversos seminários e eventos foram realizados em 2017 com este tema: Diálogos em Saúde Cidades, sujeitos e drogas: o cuidado em tempos sombrios, com uma mesa "Mães Órfãs: Por que isso tem sido possível?" na Faculdade de Medicina; Seminário "Mães Órfãs" (Faculdade de Direito e Ciências do Estado, Escola de Enfermagem, Faculdade de Medicina, Faculdade de Ciências Econômicas); reunião nacional da Pesquisa Observatório de Políticas e Cuidado em Saúde e Educação em Saúde, e o Seminário "De quem é o bebê?" no Centro de Referência da Juventude. A Frente Mineira de Drogas e Direitos Humanos e Conselho Regional de Psicologia de Minas Gerais realizaram o evento "O Estado que cuida ou o Estado que sequestra?"; o Seminário "A construção da rede de atenção às mulheres e adolescentes usuárias de álcool e outras drogas e seus filhos recém-nascidos" organizado pelo Governo de Minas Gerais e o Fórum Estadual de Enfrentamento à Violência contra a Mulher; a mesa-redonda "Abrigamento compulsório de bebês de mães com diagnóstico de drogadição" no I Seminário Humanização do Nascimento - diálogos sobre a assistência ao parto promovido pelo Instituto
Pauline Reichstul. O Ateliê de Redução de Danos e o Observatório de Políticas e Cuidado em Saúde da UFMG também fizeram diversos encontros sobre o tema.

Foi alcançada a visibilidade necessária para a vinda à $\mathrm{BH}$ de uma missão especial formada por membros da Secretaria Nacional de Direitos Humanos, Conselho Nacional de Justiça, Ministério da Saúde e Corregedoria do Ministério Público que entrevistou os diversos atores envolvidos como o Juiz da Vara da Infância, desembargadores, promotores, defensores públicos, representantes das Secretarias Municipais e Estaduais de Saúde e da Assistência Social, assim como membros do movimento, para uma escuta e avaliação da situação. A reunião com o movimento teve seis horas de entrevista com cerca de 30 participantes, além do ato de mobilização realizado na porta da Faculdade de Medicina da UFMG.

Como resultado, no dia 7 de agosto de 2017, a Corregedoria-Geral de Justiça de Minas Gerais (CGJ) oficializou a suspensão da Portaria 03/VCIJBH/2016. Foi apresentada uma Minuta para uma nova Portaria, encaminhada para a Corregedoria Geral de Justiça. A suspensão da portaria certamente foi reflexo da pressão dos movimentos sociais da cidade. No entanto, vários questionamentos foram realizados pelos grupos de assessoria jurídica à nova proposta. Perpetua desvios importantes com relação ao respeito e autonomia do Executivo na prestação da assistência e definição dos fluxos de atenção 
e cuidado. Ressalte-se ainda que, segundo relato de membros desta Missão Nacional, o Juizado da Infância e da Adolescência foi demandado a apresentar o relatório de 120 crianças abrigadas desde a publicação da Portaria 03/VCIJBH/2016, uma vez que os respectivos processos não foram distribuídos, ou seja, não foram disponibilizados para avaliação, outra grave violação à transparência e acesso dos interessados na defesa dessas mulheres e crianças.

Outra ação de expressão foi o suporte técnico para a Ação Civil Pública da Defensoria Pública de Minas Gerais em 2017 que pleiteou os direitos das mães ao menos visitarem seus filhos diariamente e também para amamentação. Disparou-se na cidade a discussão institucional sobre a importância de se manter o aleitamento para a criança abrigada, inclusive com referências atualizadas na literatura baseada em evidências científicas, que desmontam a ideia banalizada de que usuárias de drogas não podem amamentar, observando-se determinados cuidados.

Também como expressão do movimento foi publicado em 25 de novembro o Fluxo de atendimento no município por meio da PORTARIA CONJUNTA SMSA/SMASAC N.은 0001/2017 que estabelece diretrizes para a articulação e proteção social intersetorial e institui Fluxograma de Atenção às Gestantes, Puérperas e Bebês em Situação de Vulnerabilidade, Risco Social e Pessoal. ${ }^{42}$
Desafios, perspectivas e impacto em âmbito nacional

O impacto das ações do movimento "De quem é este bebê?" pressionou os autores das medidas que culminaram com abrigamentos compulsórios e injustos. Houve retaliações com perseguições pessoais e intimidação dirigidas às lideranças que despontaram nas ações de proteção dos direitos das mães e crianças. Além das duas pediatras que perderam suas funções de coordenação na SMSA, dois Conselheiros Municipais de Saúde, entre eles o presidente do Conselho, foram alvos de processo criminal motivado pela deliberação do colegiado sobre o tema. Além disso, uma Defensora Pública de MG recebeu pressões e denúncia na Ouvidoria após a ação no Conselho Nacional de Justiça ( $C N J$ ) para impugnar a Portaria 03/VCIJBH/2016.

Sabe-se que essas situações são correntes em outros estados, apenas não foram institucionalizadas ou formalizadas pelo poder judiciário como ocorreu em $\mathrm{BH}$. A resposta a esta ação de pretensa legalidade foi coletiva e intensiva em $\mathrm{BH}$, reação esperada em uma cidade que tem uma tradição de trabalho e conquistas expressivas na área da Saúde e de Políticas Sociais.

Processos semelhantes na mesma linha de obstrução e impedimento e da maternidade para mães negras, pobres e usuárias de drogas ativaram o debate em nível nacional, com a troca de experiências em forma de seminário e 
encontros e a participação de diferentes atores. Ações no âmbito nacional persistem com a formação de grupos de mobilização envolvendo cidades e pessoas que estão testemunhando o mesmo processo de arbitrariedade, como na reunião realizada durante a Conferência Nacional de Saúde das Mulheres e Congresso Mundial de Mulheres com representantes das cidades de Porto Alegre, São Paulo, Goiânia, Mato Grosso do Sul, Distrito Federal, Tocantins e Rio de Janeiro.

Em 5 de setembro houve uma Audiência Pública no Congresso Federal tratando do tema com representantes do movimento de $\mathrm{BH}$ e encaminhamento para a constituição de um grupo de trabalho do Legislativo Federal que fará uma avaliação com uma visita local à cidade. E assim, espera-se que a situação atual de violação seja interrompida e revertido o mal feito dentro das possibilidades de reparação (im)possível que marcaram essas histórias.

\section{Considerações Finais}

O movimento "De quem é este bebê?" não se opõe à adoção. Os casais que estão à espera de uma criança precisam e têm o direito de se sentirem seguros de que todo o processo de adoção seja feito dentro da lei, com total respeito aos direitos de todas as pessoas envolvidas. Entretanto, defende-se o direito das mães e famílias, em qualquer situação, de serem auxiliadas, assistidas e acolhidas para que seja possível a elas cuidarem dos seus bebês se assim desejarem. Muitas mulheres que se encontravam em situação de grande vulnerabilidade, após descobrirem a gravidez fizeram grandes esforços para mudarem sua trajetória de vida e se prepararam para receber sua criança: voltaram para suas famílias, começaram um tratamento, conseguiram um emprego. No entanto, tiveram seus filhos retirados. Foram punidas por episódios do seu passado, marcado pela pobreza, violência e abandono. As famílias perderam o vínculo com seus netos, sobrinhos, irmãos. Sentem sua falta, não sabem nada sobre o bebê e querem o seu convívio.

A separação da mãe e da família a que essas crianças estão sendo submetidas, muitas delas injustificáveis, são situações de violências que deixarão marcas para sempre no seu psiquismo, da mesma forma para outras pessoas envolvidas. Todo ser humano tem o direito de saber sua história, sua identidade e de manter conexões com sua família e comunidade. As crianças apartadas de suas famílias perderam esse direito antes de esgotadas todas as possibilidades de cuidado, apoio e amparo.

Fica o questionamento do que será feito a partir disso e de que maneira poderemos reparar perdas tão profundas, uma marca lastimável para a sociedade. Fica na história mais uma marca perversa do racismo em nosso país. 


\section{Referências}

${ }^{1}$ De quem é este bebê? Por mais saúde e menos abrigamentos em BH [Internet]. [citado 23 set 2017]. Disponível em: https://dequemeestebebe.wordpress.com

${ }^{2}$ Recomendação no 5/PJIJCBH/MPMG, de 16 de junho de 2014. Recomendação aos médicos, profissionais de saúde, diretores, gerentes e responsáveis por maternidades e estabelecimentos de saúde. Belo Horizonte: Ministério Público do Estado de Minas Gerais; 2014.

${ }^{3}$ Recomendação no 6/ PJIJCBH/MPMG, de 06 de agosto de 2014. Recomendação aos médicos, profissionais de saúde, Agentes Comunitários de Saúde, gerentes e responsáveis por Unidades Básicas de Saúde. Belo Horizonte: Ministério Público do Estado de Minas Gerais; 2014.

${ }^{4}$ Portaria no 3/VCIJBH, de 22 de julho de 2016. Dispõe sobre o procedimento para encaminhamento de crianças recémnascidas e dos genitores ao Juízo da Infância e da Juventude, assim como, oitiva destes, nos casos de graves suspeitas de situação de risco, e sobre o procedimento para aplicação de medidas de proteção. Diário do Judiciário Eletrônico TJMG. [ Internet] 201625 jul [citado 23 set 2017]:29-33. Disponível e m: http:// ftp.tjmg.jus.br/juridico/diario/index.jsp?dia=2207\&completa=2inst\%7Cadm

${ }^{5}$ Tribunal de Justiça de Minas Gerais. Minuta de portaria processo de medidas de proteção: Suspensão dos efeitos da Portaria no3 da Vara da Infância e da Juventude de Belo Horizonte de 2016 [Internet]. [citado 23 set 2017].

${ }^{6}$ Lei № 8.069, de 13 de julho de 1990. Estatuto da Criança e do Adolescente. Diário Oficial da República Federativa do Brasil, Brasília. [Internet] 1990 [citado 23 set 2017]. Disponível e m: http://www.planalto.gov.br/ccivil_03/LEIS/L8069.htm

${ }^{7}$ Kiefer S. MP determina que bebês de mães usuárias de crack sejam levados para abrigos em BH. Jornal Estado de Minas.

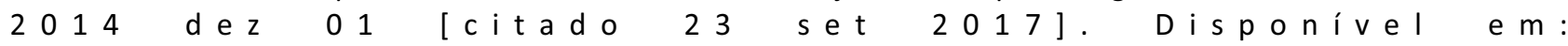
https://www.em.com.br/app/noticia/gerais/2014/12/01/interna_gerais,595140/bebes-de-viciadas-em-crack-saolevados-para-abrigos-em-bh.shtml

${ }^{8}$ Ferreira B. Determinação de MP para casos de mães viciadas gera polêmica. Jornal O Tempo. 2014 nov 13 [citado 23 set 2017]. Disponível em: http://www.otempo.com.br/ cidades/determina\%C3\%A7\%C3\%A3o-de-mp-para-casos-dem\%C3\%A3es-viciadas-gera-pol\%C3\%AAmica-1.946423

${ }^{9}$ Secretaria Municipal de Saúde de Belo Horizonte. Comissão Perinatal. Ofício no 76/2014. Recomendação para abordagem de mães usuárias de álcool e drogas para as maternidades do SUS-BH 29 ago 2014 [Internet]. [citado 23 set 2017 ] Disponível em: https://dequemeestebebe.files.wordpress.com/2017/04/ofc3adcio-76-comissc3a3o-perinatalrecomendac3a7c3b5es-maternidades-sus-bh-usuc3a1rias-de-c3a1lcool-e-drogas-1.doc

${ }^{10}$ Programa Nacional de Direitos Humanos. 3 - PNDH-3. [citado 23 set 2017]. Disponível em: http://www.sdh.gov.br/assuntos/direito-para-todos/programas/pdfs/programa-nacional-de-direitos-humanos-pndh-3

${ }^{11} \mathrm{Manifesto}$ "De quem é este bebê?" [citado 23 set 2017]. Disponível e m: https://dequemeestebebe.files.wordpress.com/2017/04/manisfesto-contra-o-abrigamento-compulsc3b3rio-assinadopor-diversas-entidades.doc

${ }^{12}$ Defensoria Pública da União e Defensoria do Estado de Minas Gerais. Recomendação Conjunta Defensorias Pública da União e do Estado de Minas Gerais [Internet]. [citado 23 set 2017]. Disponível em: http://www.cressmg.org.br/arquivos/Recomendacao\%20Conjunta\%20Defensorias.pdf

${ }^{13}$ Kiefer S. Juiz da Infância de BH critica Conselho de Saúde por não avisar nascimento de filhos do crack. Jornal Estado de Minas. 2015 jan 22 [citado 23 set 2017]. Disponível em:

${ }^{14}$ Conselho Municipal de Saúde de Belo Horizonte. Câmara Técnica de Saneamento e Políticas Intersetoriais N.o 151/2014. Parecer no - 151.2014 dez 9. [citado 23 set 2017 ]. Disponível e m : https://dequemeestebebe.files.wordpress.com/2017/04/parecer-151-14-ctspi-sobre-recomendac3a7ao-05-e-06mpjif-1.pdf

${ }^{15}$ Conselho Municipal de Saúde de Belo Horizonte. Resolução no 377/15 jan 2015. Diário Oficial do Município. [citado 23 set 2017]. Disponível em:

${ }^{16}$ Conselho Municipal dos Direitos da Criança e do Adolescente de Belo Horizonte. Deliberação no111. 2015 fev 09. [citado 23 set 2017]. Disponível em: https://www.em. com.br/app/noticia/gerais/2014/12/01/interna_gerais,595140/bebesde-viciadas-em-crack-sao-levados-p ara-abrigos-em-bh.shtml 
${ }^{17}$ Ministério da Saúde (BR). Secretaria de Atenção à Saúde. Secretaria de Gestão Estratégica e Participativa. Nota Técnica Conjunta no 001.16 set 2015 [citado 23 set 2017]. Disponível em: https://dequemeestebebe.files.wordpress.com/ 2017/ 04/ministc3a9rio-da-sac3bade-nota-tc3a9cnica-diretrizes-e-fluxograma-mulher-situac3a7c 3a3o-de-rua-2015.pdf

${ }^{18}$ Resoluções do Ministério Público serão discutidas em Audiência Pública. Portal online do Conselho Regional de Psicologia [Internet] [citado 23 set 2017]. Disponível em: http://www.crpmg.org.br/GeraConteudo.asp?materialD=4261

${ }^{19}$ Adoção compulsória de bebê de usuária de drogas é condenada. Portal online da Assembleia Legislativa de Minas Gerais. [citado 23 set 2017]. Disponível em:

${ }^{20}$ Feuerwerker LCM. Micropolítica e saúde: produção do cuidado, gestão e formação. Porto Alegre: Rede UNIDA; 2014. $174 \mathrm{p}$.

${ }^{21}$ Canguilhem G. O normal e o patológico. Rio de Janeiro: Editora Forense Universitária; 1990.

${ }^{22}$ Foucault, M. História da Sexualidade I: a vontade de saber; tradução de Maria Thereza da Costa Albuquerque e J.A. Guilhon Albuquerque. 7.ed. Rio de Janeiro: Edições Graal; 1988.

${ }^{23}$ Maciel A. "Tive que entregar meu filho para uma desconhecida". Pública - Agência de reportagem e jornalismo investigativo. 2017 jul 20. [citado 23 set 2017]. Disponível em: https://apublica.org/2017/07/tive-que-entregar-meufilho-para-uma-desconhecida

${ }^{24}$ Ministério da Saúde (BR), Ministério do Desenvolvimento Social e Combate à Fome. Nota Técnica Conjunta emitida pelos

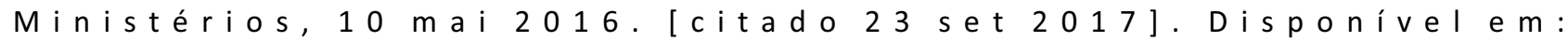
https://dequemeestebebe.files.wordpress.com/2017/04/nt_conjunta_01_mds_msaude.pdf

${ }^{25}$ Ministério da Saúde (BR), Ministério do Desenvolvimento Social e Combate à Fome. Fluxograma 10 mai 2016 . [citado 23 set 2017]. Disponível em:

${ }^{26}$ Conselho Nacional de Saúde. Recomendação № 011, 07 out 2016 [citado 23 set 2017]. Disponível em http://conselho.saude.gov.br/recomendacoes/2016/Reco011.pdf

${ }^{27}$ Secretarias de Estado da Saúde, Direitos Humanos, Participação Social e Cidadania e Trabalho e Desenvolvimento Social. Resolução Conjunta no206. 18 nov 2016 [citado 23 set 2017]. Disponível em: http://www.saude.mg.gov.br/images/documentos/Resolu\%C3\%A7\%C3\%A30\%20Conjunta_206.pdf

${ }^{28}$ Conselho Municipal de Saúde de Belo Horizonte. Resolução no 419/16. 15 dez 2016. [citado 23 set 2017]. Disponível em: https://dequemeestebebe.files.wordpress.com/2017/04/res-419-16-portaria-3.pdf

${ }^{29}$ Secretaria Municipal de Saúde de Belo Horizonte. Comissão Perinatal. Recomendação para abordagem de mães usuárias de álcool e drogas para as maternidades do SUS-BH 29 ago 2014. [citado 23 set 2017]. Disponível em:

${ }^{30}$ Secretaria Municipal de Saúde de Belo Horizonte. Comissão Perinatal. Fluxograma de Atendimento às gestantes com uso prejudicial de álcool e outras drogas. set 2016. [citado 23 set 2017]. Disponível em: https://dequemeestebebe.files.wordpress.com/2017/04/ fluxograma-gestante-uso-prejudicial-de-alccol-e-outrasdrogas-set-2016-2.pdf

${ }^{31}$ Áurea Carolina; Página da Vereadora Municipal de Belo Horizonte Áurea Carolina. [citado 23 set 2017]. Disponível em: https://ww w. facebook. com/aureacarolina/photos /a.286753371670589. 1073741828.284780545201205/433748663637725/?type=3\&theater

${ }^{32}$ Abaixo assinado: \#RevogaKalil Sônia Lansky e Márcia Parizzi ficam. abr 2016. [citado 23 set 2017]. Disponível em: https://www.change.org/p/revogakalil-s\%C3\%B4nia-lansky-e-m\%C3\%A1rcia-parizzi-ficam

${ }^{33}$ Abaixo assinado: Em defesa do direito de ser mãe! abr 2016. [citado 23 set 2017]. Disponível em:https://www.change.org/p/prefeito-de-belo-horizonte-alexandre-kalil-em-defesa-do-direito-de-sermãe ? recruiter= $29548909 \& u t m_{\text {_ source }}$ share_petition \&utm_medium=face book\&utm_campaign=share_for_starters_page\&utm_term=des-md-no_src-no_msg

${ }^{34}$ Associação Brasileira de Pós-Graduação em Saúde Coletiva. Moção de Repúdio pelo afastamento das servidoras Sonia Lansky e Marcia Parizzi. 3ㅇ Congresso Brasileiro de Política, Planejamento e Gestão em Saúde. 5 mai 2017. [citado 23 set 2017]. Disponível em: https://www.abrasco.org.br/site/eventos/congresso-brasileiro-de-politica-planejamento-egestao-em-saude/mocao-de-repudio-pelo-afastamento-das-servidoras-sonia-lansky-e-marcia-parizzi-aprovada-no-3ocongresso-de-politica/28573/

35 “De quem é esse bebê?" Página de Facebook [citado 23 set 2017]. Disponível em: https://www.facebook.com/dequemeestebebe 
${ }^{36}$ Universidade Federal de Minas Gerais. Faculdade de Direito. Programa Pólos de Cidadania. Considerações sobre a Minuta de Portaria em substituição à Portaria no 03/VCIJBH/2016 e contribuições para o debate. set de 2017 . [citado 23 set 2017]. Disponível em: https://dequemeestebebe.files.wordpress.com/2017/04/estudo-sobre-a-minuta-da-portariavcijbh.pdf

${ }^{37}$ Universidade Federal de Minas Gerais. Faculdade de Direito. Clínica de Direitos Humanos. Nota Técnica. 2017 set 01. [citado 23 set 2017]. Disponível em: https://dequemeestebebe.files.wordpress.com/2017/04/nota-tc3a9cnica-cdh.pdf

${ }^{38}$ Conselho Municipal dos Direitos da Criança e do Adolescente de Belo Horizonte. Nota Pública em Defesa do Direito à Convivência Familiar e Comunitária dos Bebês Filhos de Mulheres Usuárias de Drogas e/ou Trajetória de Vida nas Ruas do Município de Belo Horizonte. 2017 mai 26. [citado 23 set 2017]. Disponível em: http://portalpbh.pbh.gov.br/pbh/contents.do?evento=conteudo\&idConteudo=261994\&chPlc=261994

${ }^{39}$ Scott-Samuel A. Patriarchy, masculinities and health inequalities. Gac Sanit 2009; Abr;23(2):159-160. [citado 22 nov 2017].Disponível em: http://www.scielosp.org/scielo.php?script=sci_arttext\&pid=S0213-91112009000200016\&lng=en

${ }^{40}$ Foucault M. História da Sexualidade I: a vontade de saber. 7.ed. Rio de Janeiro: Edições Graal, 1988.

${ }^{41}$ "De quem é esse bebê?" Vídeo de mobilização. [citado 23 set 2017]. Disponível em: h ttps: / / w w w. yout ub e.com/ watch ? v = K 9 f ed b 2 Z v z E H Y P R I N K " https://w w w. youtube.com/watch? "https://www.youtube.com/watch?v=K9fedb2ZvzE\&t=79s"t=79s

${ }^{42}$ Prefeitura de Belo Horizonte. Portaria conjunta SMSA/SMASAC N.o 0001/2017. Diário Oficial, Belo Horizonte [citado 28 nov 2017]. Disponível em: http://portal6.pbh.gov.br/ dom/iniciaEdicao.do?method=DetalheArtigo\&pk=1187128

\section{Figura 1}

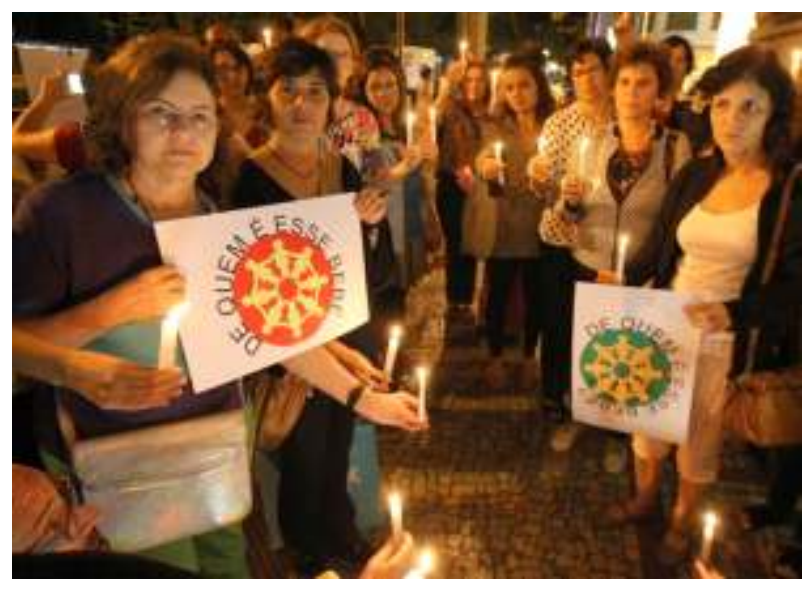

